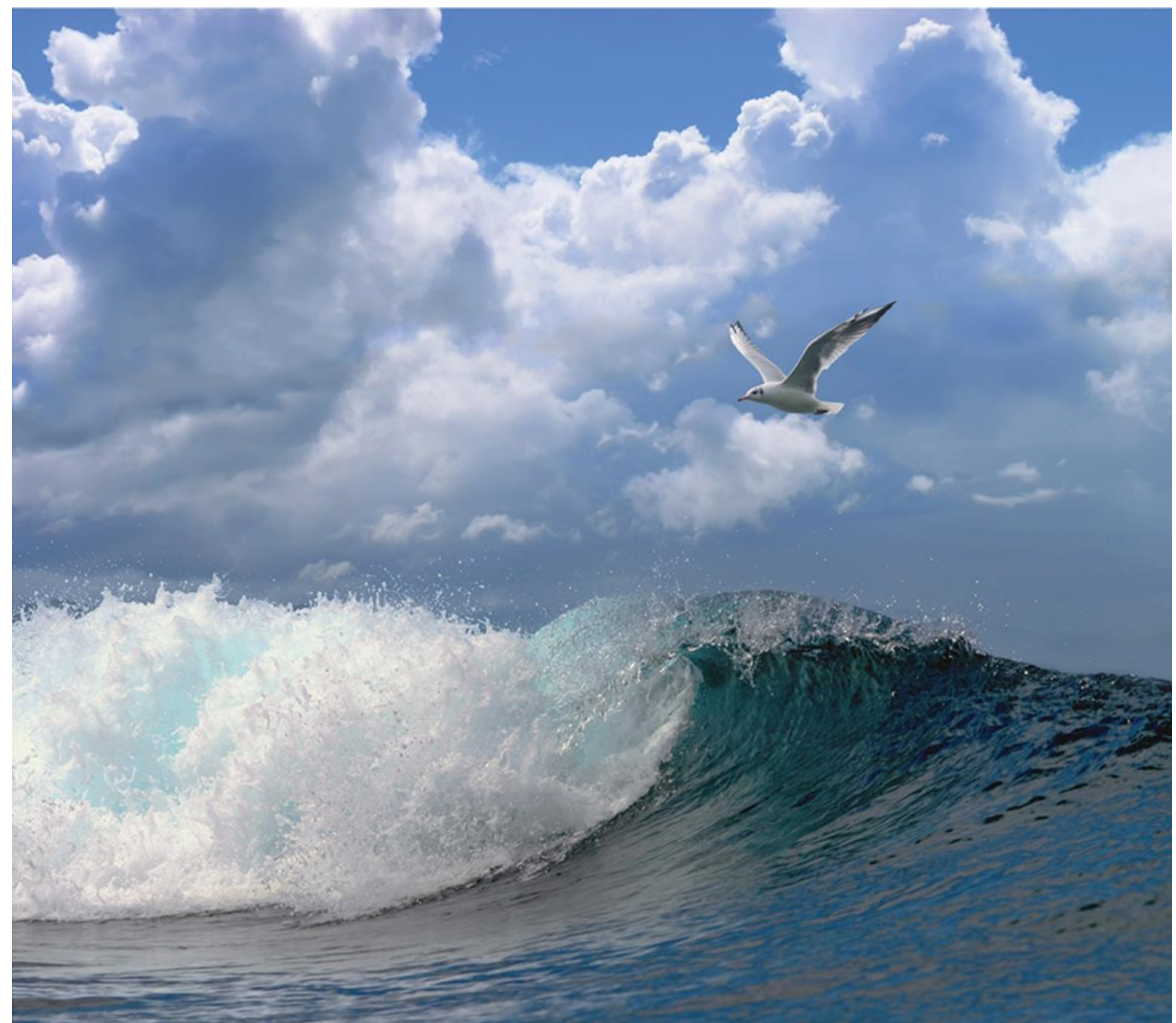

\title{
Monitoring Zandkreek
}

\section{Procesrapportage 2020}




\section{Monitoring Zandkreek}

Procesrapportage 2020

Auteur(s): $\quad$ Sarah Smith

Publicatie datum: 25 maart 2021

Wageningen Marine Research

Yerseke, maart 2021

VERTROUWELIJK Nee

Wageningen Marine Research rapport C031/21 
Opdrachtgever: Rijkswaterstaat Water, Verkeer en Leefomgeving

T.a.v.: Lucree van den Heuvel

Postbus 2232

3500 GE Utrecht

Dit rapport is gratis te downloaden van https://doi.org/10.18174/544271

Wageningen Marine Research verstrekt geen gedrukte exemplaren van rapporten.

Wageningen Marine Research is ISO 9001:2015 gecertificeerd.

\section{(C) Wageningen Marine Research}

Wageningen Marine Research, instituut binnen de rechtspersoon Stichting Wageningen Research, hierbij vertegenwoordigd door Dr.ir. J.T. Dijkman, Managing director

KvK nr. 09098104,

WMR BTW nr. NL 8113.83.696.B16.

Code BIC/SWIFT address: RABONL2U

IBAN code: NL 73 RABO 0373599285
Wageningen Marine Research aanvaardt geen aansprakelijkheid voor gevolgschade, noch voor schade welke voortvloeit uit toepassingen van de resultaten van werkzaamheden of andere gegevens verkregen van Wageningen Marine Research. Opdrachtgever vrijwaart Wageningen Marine Research van aanspraken van derden in verband met deze toepassing. Alle rechten voorbehouden. Niets uit deze uitgave mag weergegeven en/of gepubliceerd worden, gefotokopieerd of op enige andere manier gebruikt worden zonder schriftelijke toestemming van de uitgever of auteur. 


\section{Inhoud}

$1 \quad$ Inleiding $\quad 4$

1.1 Achtergrond en projectdoel $\quad 4$

1.2 Procesrapportages $\quad 6$

$2 \quad$ Projectmanagement en organisatie $\quad 7$

$\begin{array}{lll}2.1 & \text { Projectmanagement } & 7\end{array}$

$\begin{array}{lll}2.2 & \text { Samenwerking met opdrachtgever } & 7\end{array}$

$\begin{array}{llc}2.3 \text { Communicatie } & 8\end{array}$

$\begin{array}{llr}\text { Kwaliteitsmanagement } & 9\end{array}$

$\begin{array}{llr}3.1 & \text { Offerte } & 9\end{array}$

3.2 Projectuitvoering $\quad 9$

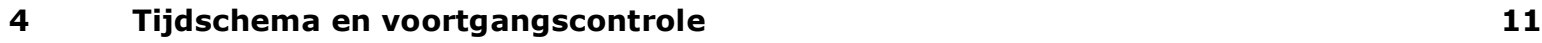

4.1 Planning 11

4.2 Stand van zaken $\quad 12$

$\begin{array}{ll}4.3 \text { Agenda } & 13\end{array}$

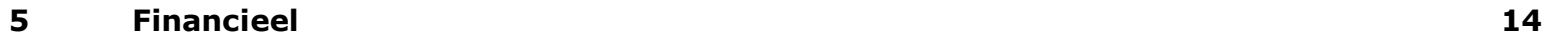

$\begin{array}{llr}\text { Kwaliteitsborging } & 15\end{array}$

$\begin{array}{ll}\text { Literatuur } & 16\end{array}$

$\begin{array}{lr}\text { Bijlage 1 Risicodossier } & 17\end{array}$

$\begin{array}{lr}\text { Verantwoording } & 19\end{array}$ 


\section{$1 \quad$ Inleiding}

\subsection{Achtergrond en projectdoel}

De vaargeul van de Zandkreek (Figuur 1., verbinding tussen de Oosterschelde en het Veerse Meer) is in de loop der jaren sterk verzand. Omdat dit tot problemen leidt voor de scheepvaart zal de geul worden uitgebaggerd. In totaal zal er ca. $125000 \mathrm{~m}^{3}$ worden gebaggerd vanuit de Zandkreekgeul. De baggerspecie zal worden gestort in stortvak 010 (Figuur 2), dat zich bevindt in het Engelsche Vaarwater. Deze locatie is door Rijkswaterstaat gekozen op basis van een modelstudie uitgevoerd door Deltares (van Duren et al., 2019) waarbij gekeken is naar verschillende verspreidingsscenario's en de effecten daarvan in de waterkolom en op de bodem in vergelijking tot verschillende natuurfuncties en gebruikersfuncties. Op verzoek van / in samenwerking met Natuurmonumenten zal een deel van de baggerspecie (50 000 tot $60.000 \mathrm{~m}^{3}$ ) worden gebruikt voor een suppletie in het Verdronken Land van Zuid-Beveland (Rattekaai, Figuur 3) (Ysebaert et al., 2020). De planning is om de werkzaamheden uit te voeren in de maanden oktober en november van 2021. Er zal daarbij gebruik worden gemaakt van een kraanschip en/of een kleine sleephopperzuiger.

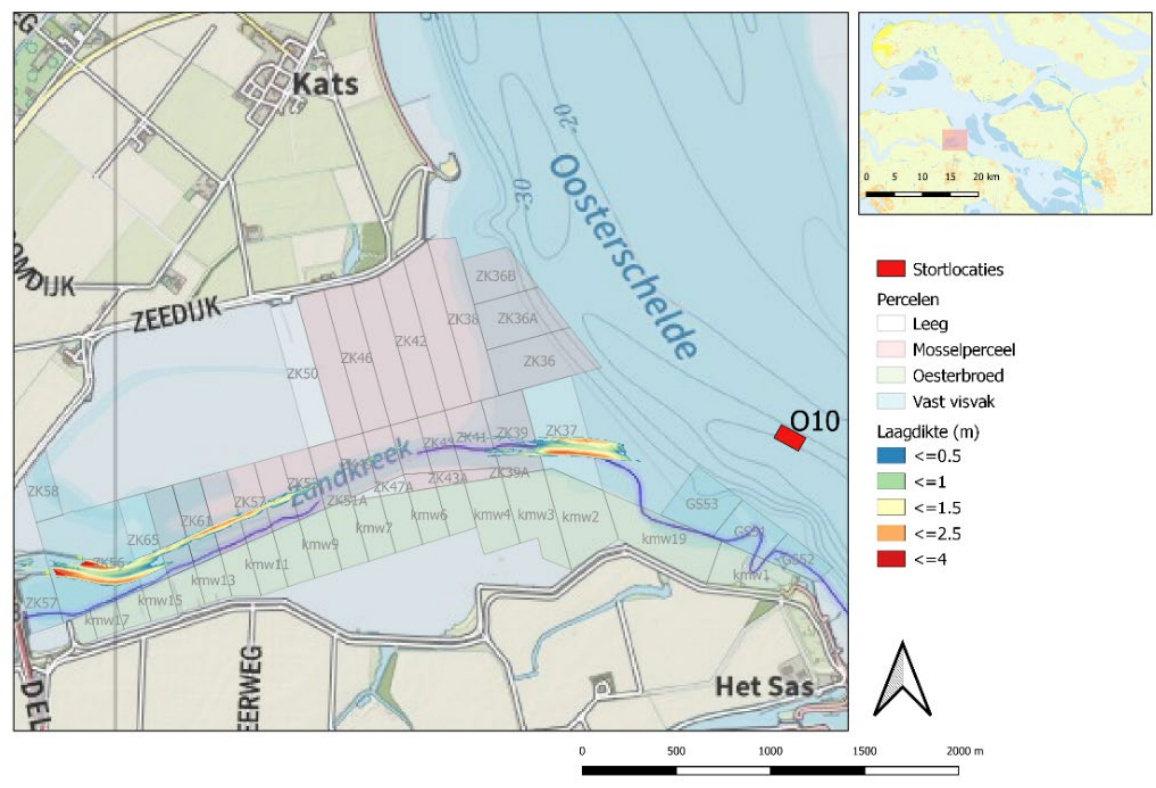

Figuur 1: Overzicht van de Zandkreek, waarbij aangegeven wordt hoeveel (laagdikte in m) er in de vaargeul weggebaggerd moet worden. Daarnaast zijn schelpdierpercelen, vaste visvakken en de stortlocatie 010 aangegeven. 


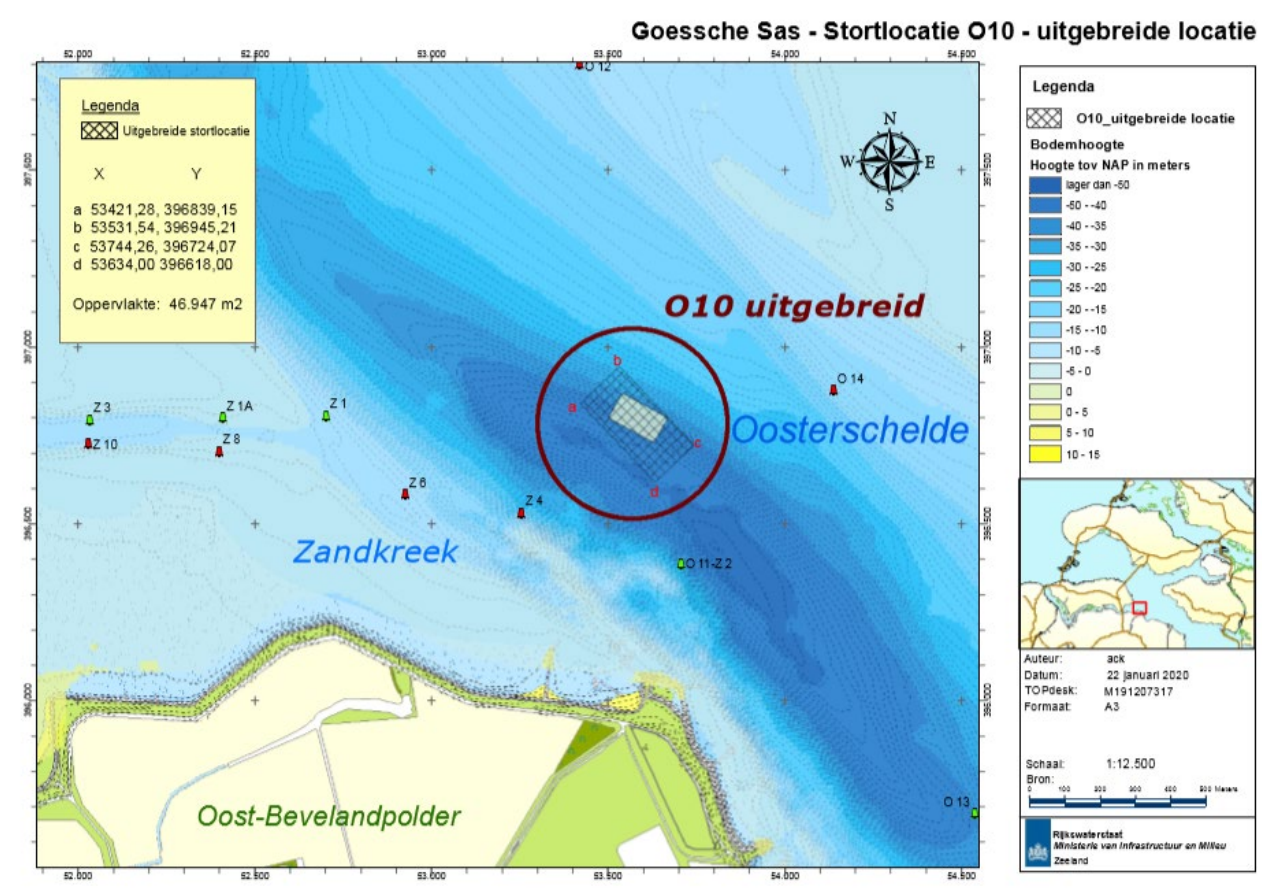

Figuur 2: De locatie van de stortlocatie $O 10$ in het Engelsche Vaarwater met de huidige grootte van de stortlocatie in (wit blokje) en de uitbreiding van de stortlocatie (raster).

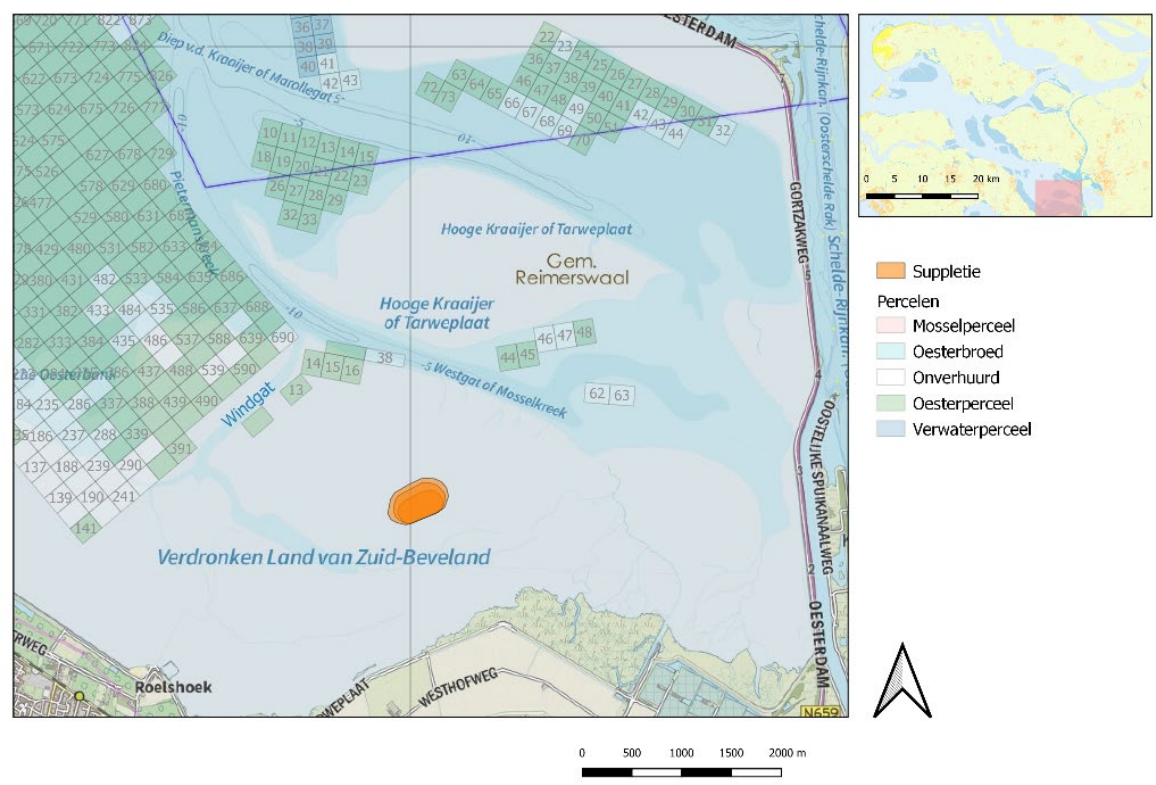

Figuur 3: Overzicht van de suppletielocatie in het Verdronken Land van Zuid-Beveland in de Oosterschelde. In oranje de locatie van de geplande suppletie. De kleurschakering geeft drie mogelijke volumes weer van de suppletie (50 $000 \mathrm{~m}^{3}, 75000 \mathrm{~m}^{3}$ en $100000 \mathrm{~m}^{3}$ baggerspecie). Ook zijn de (verhuurde en onverhuurde) oesterpercelen weergegeven.

In het gebied waar de bagger-, stort- en suppletiewerkzaamheden zullen plaatsvinden, liggen mosselpercelen, vaste vistuigvakken en oesterpercelen. Zo liggen in de Zandkreek mosselpercelen die voornamelijk worden gebruikt voor het bewaren van mosselzaad en halfwasmosselen, visvakken waar met vaste vistuigen gevist wordt op o.a. paling en kreeft, en percelen die worden gebruikt voor de invang van oesterbroed. De mosselpercelen langs de Galgenplaat in het Engelsche Vaarwater zijn een belangrijk productiegebied voor consumptiemosselen. Ook liggen er in het Engelsche Vaarwater een aantal vaste-vistuigvakken en worden er oesters gekweekt op tafels. In de Kom van de Oosterschelde waar de suppletie plaatsvindt op de slikken van het Verdronken Land van Zuid-Beveland liggen oesterkweekpercelen voor consumptie oesters en wordt er ook gevist op paling en kreeft. De werkzaamheden dienen zo min mogelijk hinder of schade te veroorzaken bij de gebruikers, met name de schelpdierkwekers en vaste vistuig vissers. 
Wageningen Marine Research heeft op verzoek van Rijkswaterstaat een monitoringsplan opgesteld om eventuele effecten van de werkzaamheden in kaart te brengen (Wijsman \& Smith, 2020). Hierbij is rekening gehouden met de meest relevante zorgpunten die kwekers en vissers tijdens een (online) stakeholderbijeenkomst op 29 mei 2020 hebben geuit. Tijdens een stakeholderbijeenkomst op 26 juni 2020 is de conceptversie van het monitoringsplan besproken met kwekers en vissers.

Rijkswaterstaat Water, Verkeer en Leefomgeving heeft op 17 december 2020 opdracht verleend aan Wageningen Marine Research (RWS-2020/57052) voor de uitvoering van het project "Uitvoering monitoringsactiviteiten Zandkreek". De opdrachtverlening is gedaan binnen de Raamovereenkomst (31105620, 11-05-2015) tussen Rijkswaterstaat en Wageningen Research voor het leveren van advies en kennis ter ondersteuning van de werkzaamheden van Rijkswaterstaat.

Het doel van deze opdracht is het (deels) uitvoeren en coördineren van de monitoring-activiteiten in het kader van de potentiele effecten van de bagger-, stort- en suppleerwerkzaamheden in resp. de Zandkreek, het Engelsche Vaarwater en op de slikken van het Verdronken Land van Zuid-Beveland op de kweekpercelen en visvakken. WMR voert de monitoringsactiviteiten uit zoals voorgesteld in het monitoringsplan (Wijsman \& Smith, 2020), aangepast op basis van de nieuwe planning van de baggerwerkzaamheden in de Zandkreek. Om de effecten van de baggerwerkzaamheden in de Zandkreek, het storten in het Engelsche Vaarwater en de aanleg van de suppletie in het Verdronken Land van Zuid-Bevelend op een eventuele schade op de percelen en in de visvakken te kunnen aantonen is een uitgebreid monitoringprogramma nodig vanwege de veelheid aan mogelijke oorzaakeffect relaties. De voorgestelde monitoring uit het monitoringsplan bestaat uit een 6-tal onderwerpen:

1. Registratie baggervolumes;

2. Metingen zwevend stof;

3. Analyse veilinggegevens mosselkweek;

4. Analyse zakboekjes;

5. Bemonstering mosselpercelen;

6. Invangsucces en ontwikkeling oesterbroed op de oesterkweekpercelen.

\subsection{Procesrapportages}

Met Rijkswaterstaat is afgesproken dat WMR jaarlijks een procesrapportage opstelt om een overzicht te geven van de voortgang van het project. Voorliggend document is de jaarlijkse procesrapportage over het jaar 2020.

De procesrapportage bevat de volgende onderdelen.

- Projectmanagement en organisatie;

- Kwaliteitsmanagement;

- Tijdschema en voortgangscontrole;

- Financieel overzicht

In de bijlage staat het risicodossier. 


\section{Projectmanagement en organisatie}

\subsection{Projectmanagement}

De uitvoering van het project is onder verantwoordelijkheid van Wageningen Marine Research. Voor onderdelen zullen andere partijen worden ingezet.

Het projectmanagement wordt vormgegeven door een team van personen binnen Wageningen Marine Research en Rijkswaterstaat. De projectleiding is in handen van Sarah Smith. De Projectleider stuurt de medewerkers aan en is verantwoordelijk voor de financiële en inhoudelijke voortgang. Tevens is de projectleider de contactpersoon voor de opdrachtgever. De Projectcontroller bewaakt de financiële voortgang van het project. Dit gebeurt onder andere tijdens het financiële projectoverleg (FPO, ca 4x per jaar). Daarnaast wordt er 3 tot 4 keer per jaar een projectvoortgangsoverleg (PVO) gevoerd met een MT-lid. Tijdens dit overleg wordt de inhoudelijke voortgang en de capaciteitsplanning besproken. Van het FPO wordt een verslag gemaakt met daarin de actiepunten die zijn afgesproken. De Reisleider (Sarah Smith (WMR) / GertJan van Veen (RVO)) is verantwoordelijk voor de uitvoering van het veldwerk. Zij/hij zorgt ervoor dat het veldwerk wordt uitgevoerd volgens de protocollen. De data worden na verzameling gecheckt door de reisleider en de Analist. Gert Jan van Veen (RVO) is alleen betrokken bij de bemonstering op de mosselpercelen. De reisleider voor de bemonstering op de oesterpercelen is Sarah Smith of een andere collega van WMR.

Het project wordt uitgevoerd volgens het Kwaliteitsmanagementsysteem van Wageningen Marine Research. De Projectleider is hiervoor verantwoordelijk. De Kwaliteitsadviseur en de Projectcontroller hebben hierbij een controlerende en adviserende taak.

De inhoudelijke rapporten van WMR worden inhoudelijk gereviewd door een senior onderzoeker die niet inhoudelijk betrokken is bij het Zandkreek project. Naast de inhoudelijk reviewer zal ook het verantwoordelijk Directielid goedkeuring dienen te geven voordat een rapport wordt opgeleverd.

De Adviseur omgeving bij Rijkswaterstaat (Alice van Goudswaard, vervanger Lucree van den Heuvel) is het eerste aanspreekpunt van de Projectleider bij WMR m.b.t. communicatie over het project richting stakeholders. De Projectleider bij Rijkswaterstaat (Frank Gijzel) is het eerste aanspreekpunt van de Projectleider bij WMR m.b.t. de projectproducten. Daarnaast is Eric van Zanten betrokken als Adviseur specialist Rijkswaterstaat.

\subsection{Samenwerking met opdrachtgever}

De samenwerking tussen Wageningen Marine Research en Rijkswaterstaat zal voornamelijk lopen via de Projectleider bij Wageningen Marine Research (Sarah Smith) en de Projectbegeleider bij Rijkswaterstaat (Alice van Goudswaard). Zij zullen elkaar telefonisch en per e-mail op de hoogte houden van voortgang en ontwikkelingen binnen het project.

Daarnaast zijn er een aantal meer formele contactmomenten tussen Wageningen Marine Research en Rijkswaterstaat:

- Startbijeenkomst in het voorjaar 2021 (Q1) ter afstemming van de geplande werkzaamheden van dat jaar.

- Kick-off bijeenkomst met stakeholders (perceelhouders en vertegenwoordigers belangenorganisaties) gepland in juni 2021, waarbij de stand van zaken van de geplande baggerwerkzaamheden en het monitoringsproject gepresenteerd wordt aan de betrokken stakeholders. 
- Tussentijds overleg vlak voor start van de baggerwerkzaamheden in het najaar 2021 ter afstemming van de geplande baggerwerkzaamheden in oktober/november 2021.

- Tussentijds overleg vlak na afronding van de baggerwerkzaamheden in 2022 (Q1) om de uitgevoerde werkzaamheden en eventuele klachten te bespreken.

- Tussentijdse bijeenkomst met stakeholders in 2022 (Q2), de stand van zaken van de uitgevoerde baggerwerkzaamheden en het monitoringsproject gepresenteerd wordt aan de betrokken stakeholders.

- Eindbijeenkomst in 2023 (Q2) om de conceptversie van het eindrapport en afronding van het project te bespreken.

- Afsluitende bijeenkomst met stakeholders in 2023 (Q2), waarbij de afronding van de monitoringswerkzaamheden wordt gepresenteerd aan de stakeholders.

\subsection{Communicatie}

Resultaten die voortvloeien uit het onderzoek zullen na afloop van het project openbaar gemaakt worden. Op publicatie van RWS onderzoek is het communicatieprotocol van toepassing waarin de resultaten twee maanden na oplevering van het resultaat openbaar gemaakt zullen worden. De rapportages komen daarmee beschikbaar op de website van Wageningen University \& Research.

Rijkswaterstaat is verantwoordelijk voor de publiekscommunicatie. Wageningen Marine Research zal op verzoek van de Projectbegeleider bij Rijkswaterstaat nodige gegevens en informatie verstrekken. 


\section{Kwaliteitsmanagement}

Het project is door Rijkwaterstaat uitbesteed aan Wageningen Marine Research via de Raamovereenkomst tussen Rijkswaterstaat en Wageningen Research (31105620, 11-05-2015) voor het leveren van advies en kennis ter ondersteuning van de werkzaamheden van RWS. De projecten worden uitgevoerd volgens het kwaliteitsmanagementplan WR voor RWS (De Bie et al., 2017). Naast het reguliere ISO 9001:2008 gecertificeerde kwaliteitsmanagementsysteem van Wageningen Marine Research gelden er voor de projecten via de Raamovereenkomst aanvullende procedures (zie ook De Bie et al., 2017).

In dit hoofdstuk wordt een overzicht gegeven voor de relevante procedures tijdens de offertefase en de uitvoeringsfase.

\subsection{Offerte}

Sarah Smith (Wageningen Marine Research) is betrokken geweest bij de totstandkoming van het ontwerp van de monitoring (Wijsman \& Smith, 2020) voor het monitoringsplan Zandkreek en was daardoor inhoudelijk goed op de hoogte van de vraag in het offerteverzoek.

Relevante stappen die zijn ondernomen tijdens het offerteproces:

- Contact tussen Alice van Goudswaard (RWS) en Sarah Smith (WMR) over de inhoud concept offerte.

- Ontvangst offerteaanvraag (10 september 2020) en beoordeling middels het Intake en Risicobeoordelingsformulier

- Aanstellen Sarah Smith als offerteleider.

- Bespreken offerte-aanvraag RWS en WMR.

- Schrijven van de offerte door Sarah Smith.

- Review offerte inhoudelijk door Jeroen Wijsman, vervolgens aanpassen door Sarah Smith.

- Controle van de procedurele/financiële zaken door projectcontroller.

- Verzenden ondertekende offerte naar Rijkswaterstaat (14 december 2020).

- Ontvangst opdracht (17 december 2020).

\subsection{Projectuitvoering}

De projectuitvoering zal worden uitgevoerd volgens procedure PP02 (Het uitvoeren van een geaccepteerde opdracht) van het kwaliteitsmanagement systeem van Wageningen Marine Research.

Relevante onderdelen hiervan zijn:

- $\quad$ PL stelt projectteam samen en maakt een capaciteitsplanning conform de begroting

- De offerte wordt werkplan.

- Werkplan wordt besproken met contactpersoon Rijkswaterstaat.

- $\quad$ Op regelmatige tijden financieel projectoverleg (FPO) met de Projectcontroller (ca 4 keer per jaar) en een inhoudelijk projectvoortgangsoverleg (PVO) met verantwoordelijk directielid en Projectcontroller.

- Conceptrapport wordt geschreven in het rapporttemplate van Wageningen Marine Research.

- Conceptrapport wordt wetenschappelijk gereviewd door een collega senior onderzoeker die inhoudelijk niet is betrokken bij de uitvoering van het project.

- Conceptrapport wordt naar opdrachtgever gestuurd en nadat het is gelezen, besproken met de klant.

- Goedkeuring door Reviewer en MT.

- Oplevering van het product met aanbiedingsbrief. 
- Bemonstering/veldwerk wordt uitgevoerd volgens de protocollen in het kwaliteitshandboek van Wageningen Marine Research. Reisleider houdt hier toezicht op.

- Uitzoeken en determinatie eveneens volgens vooraf opgestelde protocollen. 


\section{$4 \quad$ Tijdschema en voortgangscontrole}

\subsection{Planning}

Het project is gestart op 1 augustus 2020 en zal doorlopen tot 31 mei 2023. De volgende activiteiten zijn gepland:

\begin{tabular}{|c|c|c|c|}
\hline Datum & Activiteit & Status & Opmerking \\
\hline Aug 2020 & $1^{\mathrm{e}}$ Visuele inspectie oester invangpercelen & Uitgevoerd & 24 augustus 2020 \\
\hline Sept 2020 & $1^{\mathrm{e}}$ Bemonstering oesterpercelen & Uitgevoerd & $16 \& 18$ september 2020 \\
\hline Okt 2020 & $1^{\mathrm{e}}$ Bemonstering mosselpercelen & Uitgevoerd & 8 oktober 2020 \\
\hline Nov 2020 & Plaatsen van 7 meetboeien & Uitgevoerd & 29 oktober 2020 \\
\hline Dec 2020 & $2^{\text {de }}$ Bemonstering mosselpercelen & Uitgevoerd & 10 december 2020 \\
\hline Feb 2021 & $3^{\text {de }}$ Bemonstering mosselpercelen & Uitgevoerd & 8 februari 2021 \\
\hline Feb 2021 & Startbijeenkomst RWS & Uitgevoerd & 23 februari 2021 \\
\hline Feb 2021 & Procesrapportage 2020 & & \\
\hline April 2021 & $2^{\text {de }}$ Bemonstering oesterpercelen & & \\
\hline April 2021 & $4^{\text {de }}$ Bemonstering mosselpercelen & & $\begin{array}{l}\text { Voorlopig gepland op } 22 \text { apri } \\
2021\end{array}$ \\
\hline April 2021 & $\begin{array}{l}\text { Verzoek om veilinggegevens mosselkweek en } \\
\text { zakboekjes }\end{array}$ & & \\
\hline Mei 2021 & $5^{\text {de }}$ Bemonstering mosselpercelen & & $\begin{array}{l}\text { Voorlopig gepland op } 27 \text { mei } \\
2021\end{array}$ \\
\hline Mei 2021 & $\begin{array}{l}\text { Voorbereidend overleg voor de Kick-off bijeenkomst in } \\
\text { juni } 2021\end{array}$ & & \\
\hline Juni 2021 & Kick-off bijeenkomst met stakeholders & & \\
\hline Juni 2021 & $6^{\text {de }}$ Bemonstering mosselpercelen & & $\begin{array}{l}\text { Voorlopig gepland op } 24 \text { juni } \\
2021\end{array}$ \\
\hline Juli 2021 & $7^{\text {de }}$ Bemonstering mosselpercelen & & N.t.b. \\
\hline Aug 2021 & $8^{\text {ste }}$ Bemonstering mosselpercelen & & $\begin{array}{l}\text { Voorlopig gepland op } 30 \\
\text { augustus } 2021\end{array}$ \\
\hline Aug 2021 & $2^{\text {de }}$ Visuele inspectie oester invangpercelen & & \\
\hline Sept 2021 & $9^{\text {de }}$ Bemonstering mosselpercelen & & $\begin{array}{l}\text { Voorlopig gepland op } 30 \\
\text { september } 2021\end{array}$ \\
\hline Sept 2021 & $3^{\text {de }}$ Bemonstering oesterpercelen & & \\
\hline Sept 2021 & Tussentijdsoverleg RWS & & \\
\hline Okt 2021 & $10^{\text {de }}$ Bemonstering mosselpercelen & & $\begin{array}{l}\text { Voorlopig gepland op } 4 \\
\text { november } 2021\end{array}$ \\
\hline Okt 2021 & Baggerwerkzaamheden Zandkreek & & \\
\hline Okt 2021 & Registratie baggerwerkzaamheden door aannemer & & \\
\hline Okt 2021 & Multi beam opnames & & \\
\hline Nov 2021 & Baggerwerkzaamheden Zandkreek & & \\
\hline Nov 2021 & Registratie baggerwerkzaamheden door aannemer & & \\
\hline Nov 2021 & Multi beam opnames & & \\
\hline Dec 2021 & $11^{\text {de }}$ Bemonstering mosselpercelen & & $\begin{array}{l}\text { Voorlopig gepland op } 16 \\
\text { december } 2021\end{array}$ \\
\hline Jan 2022 & Tussentijdsoverleg RWS & & \\
\hline Feb 2022 & $12^{\text {de }}$ Bemonstering mosselpercelen & & \\
\hline
\end{tabular}




\begin{tabular}{|c|c|c|}
\hline Datum & Activiteit & Opmerking \\
\hline Mrt 2022 & Analyse Zakboekjes (indien van toepassing) & \\
\hline Mrt 2022 & Procesrapportage 2021 & \\
\hline April 2022 & $13^{\text {de }}$ Bemonstering mosselpercelen & \\
\hline Mei 2022 & $14^{\text {de }}$ Bemonstering mosselpercelen & \\
\hline Mei 2022 & Tussentijdse bijeenkomst met stakeholders & \\
\hline Juni 2022 & $15^{\text {de }}$ Bemonstering mosselpercelen & \\
\hline Juli 2022 & $16^{\text {de }}$ Bemonstering mosselpercelen & \\
\hline Sept 2022 & $5^{\text {de }}$ Bemonstering oesterpercelen & \\
\hline Okt 2022 & $19^{\text {ste }}$ Bemonstering mosselpercelen & \\
\hline Dec 2022 & $20^{\text {ste }}$ Bemonstering mosselpercelen & \\
\hline April 2023 & Eindbijeenkomst RWS & \\
\hline Mei 2023 & Eindrapportage & \\
\hline Mei 2023 & Afsluitende bijeenkomst met stakeholders & \\
\hline
\end{tabular}

\subsection{Stand van zaken}

Registratie van baggervolumes door de aannemer vindt pas plaats tijdens de baggerwerkzaamheden in het najaar van 2021.

In overleg met Rijkswaterstaat is afgestemd dat het benaderen van de vertegenwoordigers van de belangenorganisaties voor het aanleveren van relevante veilinggegevens van de mosselkweek en zakboekjes van kwekers/vissers plaats zou vinden na officieel ontvangst van de opdracht (17 december 2020). Het opvragen van deze gegevens heeft nog niet plaatsgevonden.

In augustus 2020 zijn de visuele inspecties van de oesterpercelen in de Zandkreek uitgevoerd. Van tevoren heeft WMR contact opgenomen met de oesterkwekers met een perceel in de Zandkreek. De kwekers werden van de geplande visuele inspectie op de hoogte gesteld en hebben WMR van informatie voorzien over de betreffende percelen (o.a. bezetting). Tijdens laag water zijn op een aantal droogvallende percelen die met schelpen waren ingezaaid, verspreid over het perceel foto's gemaakt om visueel te kunnen bepalen of er zich slib heeft afgezet op de schelpen. Een kweker heeft tijdens de inspectie van zijn perceel meegekeken.

Op 16 en 18 september 2020 zijn 5 oester-invangpercelen in de Zandkreek bemonsterd. WMR heeft voor de bemonstering contact opgenomen met de kwekers op wiens perceel de monsters zijn genomen, om hen op de hoogte te stellen van de bemonstering en om eventueel aanvullende informatie op te vragen. Tijdens laag water zijn op verschillende locaties op de percelen kwadranten $\left(1 \mathrm{~m}^{2}\right)$ neergelegd. Alle levende oesters en schelpen binnen het kwadrant zijn verzameld en meegenomen naar het lab. Per monster is het aantal broedjes geteld. Van alle oesters is de lengte gemeten. Omdat de monsters te groot waren om in het geheel uit te werken is de helft van het monster uitgewerkt.

T.b.v. de zwevend stof metingen zijn eind oktober 20207 meetboeien geplaatst op de aangewezen locaties (Wijsman \& Smith, 2020). In de periode 1 december tot 14 december zijn er een 3-tal meetboeien (ZS2, ZS5 en ZS6) op drift geraakt. Een $4^{\text {de }}$ meetboei (ZS4) is later losgeraakt en gevonden medio januari 2021. Deze meetboeien zijn in februari 2021 weer teruggeplaatst door Rijkswaterstaat. In november 2020 heeft WMR een verkennend gesprek gevoerd met een derde partij voor het aanleveren van satelliet data. Er is gewacht met het uitzetten van een offerte-uitvraag tot de 
officiële ontvangst van de opdracht van Rijkswaterstaat voor WMR. De offerte-uitvraag voor de satellietdata moet nog plaatsvinden.

In de maanden oktober 2020, december 2020 en februari 2021 zijn de eerste 3 bemonsteringen uitgevoerd op de mosselpercelen in de Zandkreek en het Engelsche Vaarwater. De bemonsteringen zijn uitgevoerd met behulp van de vakdeskundige visserij van het ministerie van LNV. WMR neemt ca. twee weken voor de geplande bemonstering contact op met de kwekers met een of meerdere percelen in de Zandkreek of in het Engelsche vaarwater. WMR stelt de kwekers op de hoogte van de geplande bemonstering en vraagt om up-to-date informatie over de percelen (o.a. bezetting). Kort na de bemonstering (ca. binnen een week) ontvangen de individuele kwekers van WMR een terugkoppeling over de bemonstering van hun eigen perceel.

In oktober 2020 is de bemonstering uitgevoerd met behulp van het schip IJsselmeer van de Rijksrederij. WMR was aanwezig bij deze bemonstering. Tijdens deze bemonstering zijn in totaal 11 percelen bemonsterd. Monsters zijn meegenomen door WMR om verder uit te zoeken in het lab. In december 2020 is de bemonstering uitgevoerd met behulp van de MS Luctor van de Rijksrederij. WMR was aanwezig bij deze bemonstering. In totaal zijn 12 percelen bemonsterd. WMR heeft geen monsters meegenomen om uit te zoeken in het lab.

In februari 2021 is de bemonstering uitgevoerd met behulp van de MS Luctor van de Rijksrederij. WMR was aanwezig bij deze bemonstering. Tijdens deze bemonstering zijn in totaal 10 percelen bemonsterd. Monsters zijn meegenomen door WMR om verder uit te zoeken in het lab.

\subsection{Agenda}

- $\quad$ Startbijeenkomst tussen WMR en Rijkswaterstaat op dinsdag 23 februari 2021, 10.30-12.00.

- Voorbereidend overleg voor de Kick-off bijeenkomst tussen WMR en Rijkswaterstaat in mei 2021.

- Kick-off bijeenkomst met stakeholders (perceelhouders en vertegenwoordigers), juni 2021. 


\section{$5 \quad$ Financieel}

De totale kosten voor het project Monitoring Zandkreek bedragen $€ 321.498$,- (Excl. BTW). Dit bedrag bestaat enerzijds uit $€ 246.588$,- (Excl. B.T.W.) op basis van een vaste prijs. Anderzijds zijn er drie verschillende stelposten opgenomen van een gezamenlijk bedrag van $€ 74.910,-$ (Excl. BTW).

De betalingen geschieden in jaarlijkse termijnen volgens onderstaand schema:

Tabel 2 Overzicht van de factuurmomenten

\begin{tabular}{|c|c|c|c|}
\hline Moment & Product & Bedrag (Excl. BTW) & Status \\
\hline Feb 2022 & Procesrapportage 2021 & $€ 98.636,-$ & \\
\hline Mei 2023 & Eindrapportage & $€ 73.976$,- & \\
\hline Mei 2023 & & $€ 74.910,-$ & $\begin{array}{l}\text { Stelposten, indien van } \\
\text { toepassing. }\end{array}$ \\
\hline
\end{tabular}




\section{$6 \quad$ Kwaliteitsborging}

Wageningen Marine Research beschikt over een ISO 9001:2015 gecertificeerd kwaliteitsmanagementsysteem. Dit certificaat is geldig tot 15 december 2021. De organisatie is gecertificeerd sinds 27 februari 2001. De certificering is uitgevoerd door DNV GL. 


\section{Literatuur}

De Bie, P. A. F., E. B. Oosterkamp, M. J. C. Rozemeijer en C. A. Schmidt (2017) Kwaliteitsmanagementplan WR voor RWS. Uitwerking Raamovereenkomst. Wageningen University \& Research, Rapport, 18 pagina's.

Van Duren, L., J. A. Cado van der Lelij, J. Hanssen, S. Gaytan Aguilar en T. Van Kessel (2019) Modelstudie effecten slibpluim Zandkreek. Deltares, Rapport nummer: 11203112-002-ZKS-0004, 43 pagina's.

Wijsman, J.W.M. en S.R. Smith (2020) Monitoringsplan bagger- en stortwerkzaamheden Zandkreekgeul. Wageningen Marine Research, Rapport, 45 pagina's.

Ysebaert, T., B. Walles, J. Van der Werf, T. Van Kessel, L. De Vet, J. Hansen, L. Van Duren, T. Bouma en J. Stronkhorst (2020) Natuur Impuls Oosterschelde. Toepassingsmogelijkheden van slibrijk sediment voor de natuurbouw. Wageningen Marine Research, Rapport, 137 pagina's. 


\section{Bijlage 1 Risicodossier}

Er is een risicodossier opgesteld voor dit project. De kansen van de risico's zijn gekwantificeerd als volgt:

1. Zeer onwaarschijnlijk $(<1 \%)$

2. Onwaarschijnlijk (1-10\%)

3. Redelijk (10-40\%)

4. Waarschijnlijk (40-80\%)

5. Vrijwel zeker (> 80\%)

De impact is ook gekwantificeerd in 5 klassen:

1. Klein

2. Beperkt

3. Redelijk

4. Groot

5. Zeer groot

Het risicodossier is een levend document en zal regelmatig up-to-date worden gemaakt.

Tabel 4. Overzicht van risico's. De risico's zijn gekwantificeerd in de kolommen $K$ (kans), I (impact) en $R$ (risico $=$ kans $\mathrm{x}$ impact $)$.

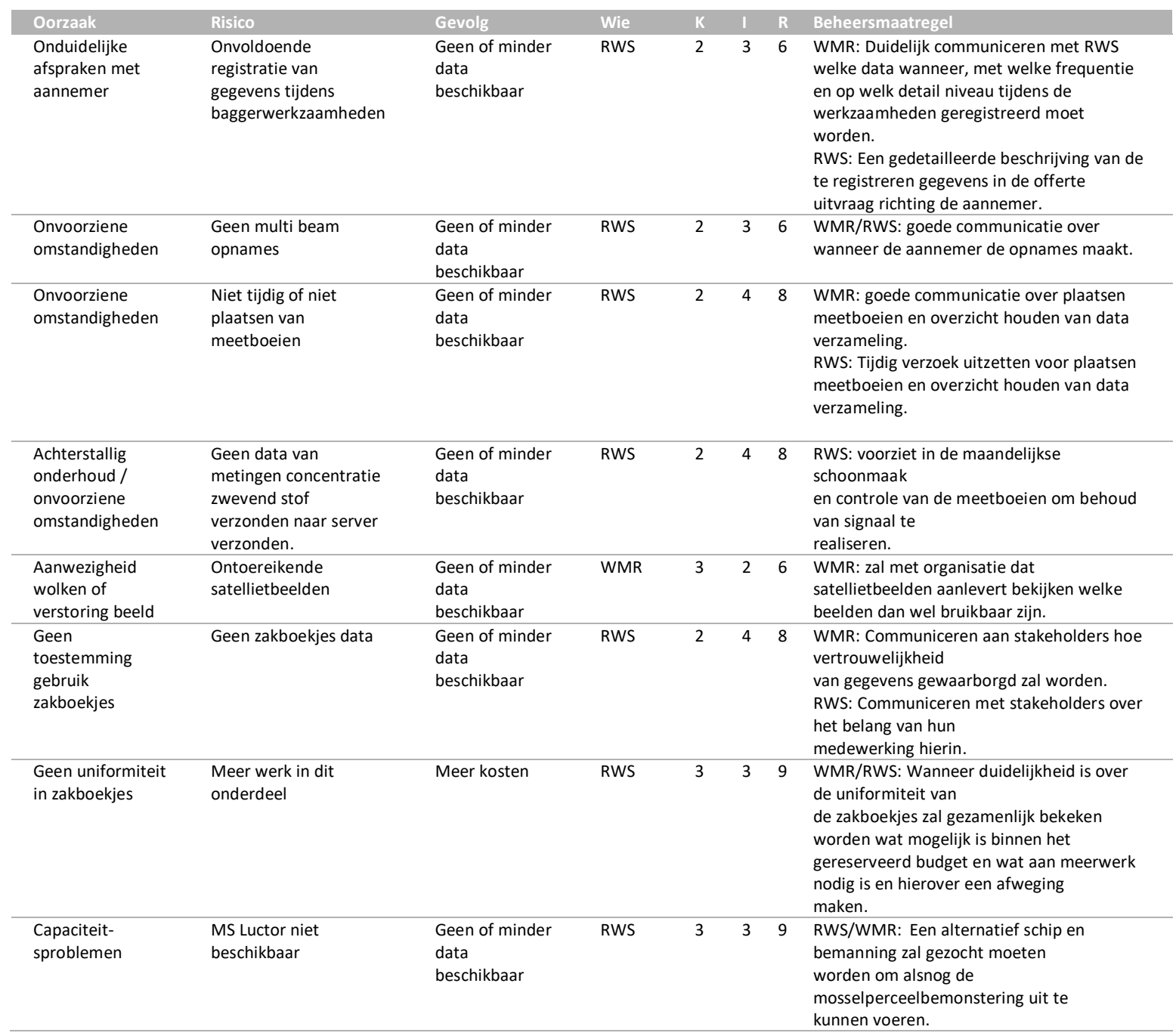




\begin{tabular}{|c|c|c|c|c|c|c|c|}
\hline Oorzaak & Risico & Gevolg & Wie & $\mathrm{K}$ & 1 & $\mathbf{R}$ & Beheersmaatregel \\
\hline $\begin{array}{l}\text { Capaciteit- } \\
\text { sproblemen }\end{array}$ & $\begin{array}{l}\text { Onvoldoende } \\
\text { mankracht }\end{array}$ & $\begin{array}{l}\text { Geen of minder } \\
\text { data } \\
\text { beschikbaar }\end{array}$ & WMR & 2 & 3 & 6 & $\begin{array}{l}\text { WMR: Tijdig plannen van de benodigde } \\
\text { werknemers. Daarnaast beschikt WMR over } \\
\text { meerdere collega's met de benodigde } \\
\text { expertise waardoor inzetbaarheid flexibel is. }\end{array}$ \\
\hline $\begin{array}{l}\text { Werken in het } \\
\text { veld en op } \\
\text { schepen }\end{array}$ & $\begin{array}{l}\text { Onveilige situatie voor } \\
\text { WMR werknemers }\end{array}$ & Ongevallen & WMR & 2 & 4 & 8 & $\begin{array}{l}\text { WMR: Er zal gewerkt worden volgens de } \\
\text { veiligheidsprotocollen voor veldwerk en } \\
\text { medewerkers die op de schepen werken } \\
\text { zullen in bezit zijn van een Basic Safety } \\
\text { Training }\end{array}$ \\
\hline $\begin{array}{l}\text { Afhankelijk van } \\
\text { derden voor deel } \\
\text { data }\end{array}$ & $\begin{array}{l}\text { Derde partijen leveren } \\
\text { niet of deels }\end{array}$ & $\begin{array}{l}\text { Geen of minder } \\
\text { data } \\
\text { beschikbaar }\end{array}$ & RWS & 2 & 4 & 8 & $\begin{array}{l}\text { WMR/RWS: Tijdig en blijvende } \\
\text { communicatie met de derde partijen } \\
\text { over de noodzaak van tijdig aanleveren van } \\
\text { data }\end{array}$ \\
\hline $\begin{array}{l}\text { Omgeschikte } \\
\text { weersomstandig- } \\
\text { heden. }\end{array}$ & Uitstel van veldwerk & $\begin{array}{l}\text { Geen of minder } \\
\text { data } \\
\text { beschikbaar }\end{array}$ & RWS & 2 & 3 & 6 & $\begin{array}{l}\text { WMR/RWS: Tijdig en blijvende } \\
\text { communicatie over planning van veldwerk }\end{array}$ \\
\hline $\begin{array}{l}\text { Bedrijfsgevoelige } \\
\text { data }\end{array}$ & $\begin{array}{l}\text { Onvoorzichtig omgaan } \\
\text { met gevoelige } \\
\text { informatie }\end{array}$ & $\begin{array}{l}\text { Gevolgen voor } \\
\text { betreffend } \\
\text { bedrijf. }\end{array}$ & WMR & 2 & 4 & 8 & $\begin{array}{l}\text { WMR: vertrouwelijkheid data waarborgen } \\
\text { door data beveiligd te bewaren } \\
\text { alleen toegankelijk voor } \\
\text { projectmedewerkers. In de rapportage(s) } \\
\text { zullen de gegevens geanonimiseerd worden. }\end{array}$ \\
\hline $\begin{array}{l}\text { Schadelijke } \\
\text { effecten van } \\
\text { werkzaamheden }\end{array}$ & $\begin{array}{l}\text { Gebruik van resultaten } \\
\text { in gerechtelijke } \\
\text { procedure }\end{array}$ & $\begin{array}{l}\text { Imago schade } \\
\text { WMR }\end{array}$ & RWS & 3 & 3 & 9 & $\begin{array}{l}\text { WMR: Sterk inzetten op transparantie van } \\
\text { het onderzoek en actief met de gebruikers } \\
\text { community overleggen over de } \\
\text { voortgang van de monitoring. } \\
\text { RWS: Actief overleg met de gebruikers over } \\
\text { de voortgang van de bagger- stort- en } \\
\text { suppletiewerkzaamheden en organiseren } \\
\text { van jaarlijkse stakeholder bijeenkomsten. }\end{array}$ \\
\hline COVID-19 & $\begin{array}{l}\text { Niet uitvoeren van } \\
\text { werkzaamheden }\end{array}$ & $\begin{array}{l}\text { Werkzaam- } \\
\text { heden gaan niet } \\
\text { zoals gepland. }\end{array}$ & WMR & 3 & 3 & 9 & $\begin{array}{l}\text { WMR: neemt contact op met RWS indien } \\
\text { aanpassing van de planning noodzakelijk is. }\end{array}$ \\
\hline
\end{tabular}




\section{Verantwoording}

Rapport C031/21

Projectnummer: 4313100140

Dit rapport is met grote zorgvuldigheid tot stand gekomen. De wetenschappelijke kwaliteit is intern getoetst door een collega-onderzoeker en het verantwoordelijk lid van het managementteam van Wageningen Marine Research

Akkoord:

Johan Craeymeersch

Senior Onderzøqk

Handtekening:

Datum:

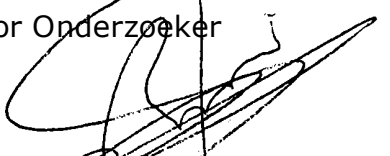

Akkoord:

Jakob Asjes

Manager Integratie

Handtekening:

Datum:

26 maart 2021 
Wageningen Marine Research

T: $+31(0) 317480900$

E: marine-research@wur.nl

www.wur.nl/marine-research

Bezoekers adres:

- Ankerpark 27, 1781 AG Den Helder

- Korringaweg 7, 4401 NT Yerseke

- Haringkade 1, 1976 CP IJmuiden
Wageningen Marine Research levert met kennis, onafhankelijk wetenschappelijk onderzoek en advies een wezenlijke bijdrage aan een duurzamer, zorgvuldiger beheer, gebruik en bescherming van de natuurlijke rijkdommen in zee-, kust- en zoetwatergebieden.

Wageningen Marine Research is onderdeel van Wageningen University \& Research. Wageningen University \& Research is het samenwerkingsverband tussen Wageningen University en Stichting Wageningen Research en heeft als missie: 'To explore the potential of nature to improve the quality of life' 